\title{
EFEKTIFITAS PAKET NATURE TERHADAP DISMENORE PADA REMAJA PUTRI
}

\author{
Ira Kartika' ${ }^{1}$, Nety Rustikayanti², Laksmi Nurul Suci ${ }^{3}$ \\ 1STIKes Dharma Husada Bandung \\ Email : irakartika45@yahoo.com \\ 2STIKes Dharma Husada Bandung \\ Email : netyrustikayanti@stikesdhb.ac.id \\ ${ }^{3}$ STIKes Dharma Husada Bandung \\ Email : laksmi26@gmail.com
}

\begin{abstract}
Background Dysmenorrhea is one of the most common gynecological problems experienced by female adolescent and can have an impact on the actions or activities of female adolescent. Dysmenorrhea makes female adolescent unable to move normally and need painkillers. This situation causes discomfort in daily physical activity. Some ways are done by female adolescent to relieve/reduce dysmenorrhea, both pharmacologically and nonpharmacologically.

Pupose The objective of the study was to identify the effectiveness of the nature package on dysmenorrhea to female adolescent.

Methods This research was a preexperiment design of quantitative research, with two group pretest posttest design with control. The total sample was 30 respondents, the sampling technique used purposive sampling. The data collection used research instruments in the form of intervention procedures and numeric rating scale sheets, which were analyzed using the Wilcoxon Rank Test.

Results showed that the most distribution of dysmenorrhea was moderate with a percentage of $60 \%$. The was the same change occurred between the control and the intervention group before and after being given the treatment with a $p$ value of 0.001 . Moreover, there were differences between the control group and the intervention group with a $p$ value of 0.007 . For the respondents in the intervention group who were given the nature package, the median of the dysmenorrhea decreased from 6.00 to 2.00 with a $p$ value $0.001 \quad(p<0.05)$ which means that the nature package was effective in reducing dysmenorrhea in female adolescent.

Conclusion There was a difference between the intervention group and the control group with the Wilcoxon rank test results $p=0.007(p<0.05)$.

SugestionTherefore, health workers are expected to increase efforts to prevent dysmenorrhea in young women in senior high schools and to collaborate with UKS officers.
\end{abstract}

Keywords: Nature Package, Raja Banana Consumption, Abdominal Stretching Exercise, Drinking Water

\section{ABSTRAK}

Latar belakang Dismenore merupakan salah satu masalah ginekologi yang paling umum dialami remaja putri dan dapat menimbulkan dampak bagi kegiatan atau aktivitas para remaja putri. dismenore membuat remaja putri tidak bisa beraktivitas secara normal dan memerlukan obat pereda sakit. Keadaan tersebut menyebabkan ketidaknyamanan dalam aktivitas fisik sehari-hari. Beberapa cara yang dilakukan remaja putri untuk menghilangkan atau menurunkan dismenore, baik secara farmakologis maupun nonfarmakologis.

Tujuan penelitian untuk mengidentifikasi efektifitas paket nature terhadap dismenore pada remaja putri.

Metode penelitian ini merupakan penelitian kuantitatif preexperimentdesign, dengan two group pretest posttest design with control. Total sampel adalah 30 responden, tekhnik pengambilan sampel menggunakan purposive sampling. Instrumen penelitian berupa prosedur intervensi dan numeric rating scale, yang dianalisis menggunakan Wilcoxon Rank Test.

Hasil penelitian didapatkan distribusi dismenore terbanyak adalah sedang dengan persentase $60 \%$. Terjadi perubahan yang sama antara kelompok kontrol dan intervensi sebelum dan sesudah diberikan perlakuan dengan nilai $p$ value 0,001 .Terdapat perbedaan antara kelompok kontrol dan kelompok intervensi dengan nilai $p$ value 0,007 . Untuk responden kelompok intervensi yang diberikan paket nature median dismenore dari 6,00 turun menjadi 2,00 dengan nilai $p$ value $0,001(p<0,05)$ yang berarti paket nature efektif dalam menurunkan dismenore pada remaja putri. 
Kesimpulan Terdapat perbedaan antara kelompok intervensi dan kelompok kontrol dengan hasil uji wilcoxon rank test $p=0,007(p<0,05)$.

Saran Petugas kesehatan diharapkan dapat meningkatkan upaya pencegahan dismenore pada remaja putri di Sekolah Menengah Atas serta dapat menjalin kerja sama dengan petugas UKS.

Kata kunci : Paket Nature, Pisang Raja, Abdominal Stretching Exercise, Air Putih

\section{PENDAHULUAN}

Remaja adalah periode peralihan dari masa anak ke masa dewasa, biasanya mulai dari usia 0-19 tahun.remaja mengalami perubahan dalam tiga aspek yaitu perkembangan psikososial, perkembangan kognitif dan perubahan fisik. Salah satu tanda perubahan fisik adalah pada remaja putri mulai mengalami menstruasi/haid (Kumalasari et al, 2012).

Menstruasi merupakan proses keluarnya darah yang terjadi secara periodik atau siklik endometrium yang secara fisiologis menandakan terbuangnya sel telur yang sudah matang dan merupakan pertanda masa reproduktif pada kehidupan seorang remaja putri (Bobak, 2004). Menstruasi dimulai antara usia 12-15 tahun dan berlangsung mencapai usia 45-50 tahun (Progestian, 2010).

Keluhan-keluhan yang sering muncul pada saat menstruasi adalah mudah tersinggung, gelisah, sukar tidur, gangguan konsentrasi, payudara mengalami pembesaran, dan gangguan yang berkenaan dengan masa haid berupa dismenore (Manuaba, 2009). Salah satu keasaan yang paling sering dirasakan oleh remaja putri saat mentsruasi yaitu dismenore.

Dismenore dikategorikan menjadi dua yaitu dismenore primer berkaitan dengan nyeri haid yang terjadi tanpa terdapat kelainan anatomis dan kelamin, sedangkan dismenore sekunder yaitu nyeri haid yang berhubungan dengan kelainan anatomis yang jelas dan masalah patologis di rongga panggul (Manuaba, 2009). Hal ini di dukung oleh penelitian yang dilakukan DEPKES tahun 2010 di Indonesia angka kejadian dismenore sebesar $64,52 \%$ yang terdiri dari $54,89 \%$ dismenore primer dan $9,36 \%$ dismenore sekunder.

Menurut Prawirohardjo (2011) dismenore membuat remaja putri tidak bisa beraktivitas secara normal dan memerlukan obat pereda sakit. Pada sebagian remaja putri, dismenore primer merupakan masalah tersendiri yang harus dialami setiap bulannya, sehingga remaja harus dapat mencari solusi yang tepat untuk mengatasinya. Banyak cara untuk menghilangkan/menurunkan dismenore, baik secara farmakologis maupun nonfarmakologis. Pengobatan pada dismenore dapat menggunakan obat analgetika (obat antinyeri).

Sebesar $80 \%$ penderita mengalami penurunan rasa nyeri menstruasi setelah minum obat penghambat prostaglandin (Speroff, 2005). Obat non-steroid anti inflamasi (NSAID) golongan non-steroid seperti ibuprofen, naproksen, asam mefenamat dan aspirin banyak digunakan sebagai terapi awal untuk dismenore, pada dosis biasa mempunyai efek samping mual, muntah, gelisah dan rasa ngantuk, sedangkan pada dosis tinggi efek samping bisa menyebabkan tekanan darah turun, peredaran darah tidak lancar dan akhirnya bisa terjadi koma.

Manajemen tanpa minum obat (nonfarmakologis) lebih aman digunakan selain sederhana, mudah dilakukan, minimal efek samping, minimal biaya dan bersifat preventif. Beberapa cara untuk meredakan dismenore yaitu kompres air hangat, massase, distraksi, latihan fisik atau exercise (yoga, abdominal stretching, senam dismenore, dan lain lain), tidur cukup, diet rendah garam, dan peningkatan penggunaan diuretik alami seperti terapi air putih. Exercise sangat dianjurkan untuk mengurangi dismenore. Exercise merupakan salah satu tekhnik relaksasi yang dapat digunakan untuk mengurangi nyeri. Hal ini disebabkan karena saat melakukan exercise tubuh akan menghasilkan endorphin.. Salah satu cara exercise untuk menurunkan intensitas dismenore adalah dengan melakukan abdominal stretching exercise yang merupakan suatu latihan peregangan otot terutama pada perut yang dilakukan selama 10 menit. Hal ini didukung dengan hasil penelitian yang menyatakan bahwa abdominal stretching exercise dan terapi air putih memberikan peningkatan yang signifikan dalam mengurangi dismenore primer (Ningsih, Setyowati \& Rahmah, 2011).

Komponen tunggal terbesar dari tubuh adalah air. Air adalah pelarut bagi semua zat terlarut dalam tubuh baik dalam bentuk suspensi maupun larutan. Air dapat menembus semua membran tubuh secara bebas. Menurut Sulistyanto (2018) bahwa pisang memiliki kandungan kalium dan vitamin B6 yang tinggi, yaitu lebih dari $400 \mathrm{mg}$ kalium per buah pisang ukuran sedang. Menurut para ahli gizi, kalium sangat diperlukan saraf, 
membantu fungsi otot dan menjaga keseimbangan cairan dalam tubuh. Kalium dalam pisang bisa membantu mencegah kram otot setelah latihan. Hal ini dibuktikan dengan penelitian yang dilakukan oleh Edo, Erma dan Ririn (2016) di SMA Muhammadiyah 01 Malang pada siswi remaja menunjukkan konsumsi pisang raja efektif terhadap penurunan nyeri haid pada dismenore primer.

Berdasarkan hasil uraian diatas dapat disimpulkan bahwa abdominal stretching exercise, terapi air putih dan konsumsi buah pisang raja dapat mengatasi dismenore. Maka peneliti mengkombinasikan ketiga cara nonfarmakologis tersebut menjadi satu yang diberi nama paket nature.

Dari hasil studi pendahuluan yang dilakukan peneliti pada tanggal 10 Januari 2019 pada petugas UKS SMA Negeri 17 Bandung dari total 220 remaja putri yang mengalami dismenore, sebanyak 44 orang mengeluh nyeri haid dengan wajah meringis, 88 orang lainnya mengeluh nyeri haid sambil memegang perut bagian bawah, 88 orangmengeluh nyeri haid sambil memegang perut bagian bawah, meeringis dan tidak dapat beraktivitas. Petugas UKS juga mengatakan penanganan yang dilakukan untuk mengurangi nyeri dengan pemberian kompres air panas. Berdasarkan latar belakang tersebut maka penulis tertarik mengadakan penelitian tentang "Efektifitas Paket Nature Terhadap Dismenore Pada Remaja Putri Di SMA Negeri 17 Bandung"

\section{METODE PENELITIAN}

Penelitian ini merupakan penelitian
kuantitatif preexperiment design dengan pendekatan two group pretest posttest design with control. Populasi dalam penelitian ini adalah remaja putri kelas $\mathrm{X}$ dan $\mathrm{XI}$ yang mengalami dismenore di SMA Negeri 17 Bandung sebanyak 220 orang dan jumlah sampel yang diteliti berjumlah 30 orang. Sampel tersebut dibagi kedalam dua kelompok yaitu kelompok intervensi 15 orang dan kelompok kontrol 15 orang dengan waktu pengambilan data 33 hari. Tekhnik pengambilan sampel menggunakan purposive sampling. Kriteria inklusi dalam penelitian ini adalah Remaja putri yang mengalami dismenore pada 1-3 hari menstruasi dalam tiga bulan terakhir berturut-turut, remaja putri yang tidak memiliki riwayat menggunakan terapi farmakologis selama dismenore dan remaja putri yang memiliki siklus haid dengan rentang waktu 2435 hari, sedangkan kriteria ekslusi adalah remaja putri yang menderita penyakit ginekologis tertentu (dismenore sekunder) dan remaja putri yang mengalami dismenore sangat berat dan tidak masuk sekolah. Variabe independen dalam penelitian ini adalah paket nature dan variabel dependen adalah tingkat dismenore pada remaja putri.

Prosedur pengumpulan data yang akan dilakukan adalah peneliti Proses kegiatan penelitian dilakukan setelah mendapatkan persetujan secara akademis, kemudian peneliti mempersiapkan surat permohonan izin untuk melakukan penelitian di SMA Negeri 17 Bandung.Setelah mendapatkan izin dari Kepala Sekolah SMA Negeri 17 Bandung, peneliti menyiapkan diri dengan melakukan latihan abdominal stretching. Peneliti datang ke SMA Negeri 17 Bandung lalu mensosialisasikan kegiatan yang akan dilakukan di SMA Negeri 17 Bandung.

Peneliti bekerja sama dengan guru dan petugas UKS selama penelitian berlangsung dan memberikan penjelasan mengenai hal-hal yang berkaitan dengan penelitian, serta meminta izin disediakan ruangan untuk pelaksanaan latihan abdominal stretching. Sebelum penelitian dilakukan, peneliti melakukan screening terlebih dahulu untuk memilih remaja putri yang akan menjadi responden dan memilih responden yang memiliki tanggal menstruasi yang berdekatan.Peneliti menentukan jumlah dan nama responden yang termasuk kriteria inklusi dengan total berjumlah 30 remaja putri.Peneliti mengumpulkan responden dalam satu ruangan dan membagi responden dalam 2 kelompok (intervensi dan kontrol). Peneliti menjelaskan tujuan prosedur penelitian dan teknik penelitian pada responden.Peneliti meminta persetujuan dari calon responden untuk berpartisipasi dalam penelitian. Setiap responden diberikan kebebasan memberikan persetujuan atau menolak untuk menjadi subjek penelitian. Setelah calon responden menyatakan bersedia untuk mengikuti prosedur penelitian, maka responden diminta untuk menanda tangani lembar informed consent yang telah disiapkan peneliti. Peneliti memberikan Numeric Rating Scale pada responden dan menjelaskan cara mengisi lembar pengukuran tersebut.

Peneliti memberikan penjelasan mengenai paket Nature pada kelompok intervensi, dimana paket tersebut terdiri dari abdominal stretching exercise, minum air putih dan konsumsi buah pisang raja yang diberikan selama seminggu sebelum menstruasi dengan aturan sebagai berikut : abdominal stretching exercise dilakukan selama 10 menit dalam waktu 1 minggu dengan frekuensi 3 kali, minum air putih 10 gelas perhari dengan cara sebagai berikut : dua gelas air putih diminum pagi hari setelah bangun tidur sebelum sarapan, dua gelas 1,5 jam sebelum makan pagi, makan siang 
dan makan malam, dua gelas sebelum tidur malam, gelas yang digunakan berukuran isi $250 \mathrm{cc}$ dan konsumsi buah pisang raja $100 \mathrm{~g}$ dengan frekuensi 1 kali sehari saat pagi hari yang akan disediakan oleh peneliti.

Kemudian pada kelompok kontrol dilakukan perlakuan yang biasa responden gunakan ketika dismenore seperti kompres air panas, minum air hangat dan membalurkan minyak kayu putih di bagian bawah perut.Peneliti membagikan pedoman paket nature pada kelompok intervensi. Peneliti mengajarkan salah satu dari kombinasi paket nature yaitu abdominal stretching exercise pada kelompok intervensi. Setiap pagi peneliti datang ke sekolah untuk membagikan pisang raja kepada responden yang sudah terjadwal. Saat terjadi dismenore pada menstruasi hari pertama, responden melaporkan pada peneliti melalui via aplikasi whatsapp, lalu peneliti memberikan lembar pengukuran dismenore (Numeric Rating Scale), selanjutnya responden mengisi dismenore yang dirasakan saat itu. Responden yang telah diberikan paket nature selama seminggu sebelum menstruasi akan diobservasi kembali oleh peneliti pada hari pertama terjadinya menstruasi. Hasil observasi setiap responden akan didokumentasikan pada lembar observasi paket nature.

Peneliti meminta responden untuk mengisi kembali lembar pengukuran dismenore (Numeric Rating Scale) pada hari pertama menstruasi setelah diberikan paket nature. Peneliti memberikan reinforcement positif pada semua responden atas keterlibatannya dalam penelitian.
Pengumpulan data dilakukan melalui screening kemudian dilakukan pretest dan posttest baik pada kelompok kontrol maupun kelompok intervensi. Pengukuran dismenore menggunakan Numeric Rating Scale dan di observasi dengan lembar observasi yang sudah disediakan peneliti.

\section{HASIL DAN PEMBAHASAN}

Penelitian mengenai Efektifitas Paket Nature Terhadap Dismenore Pada Remaja Putri Di SMA Negeri 17 Bandung telah dilaksanakan pada tanggal 22 April - 25 Mei 2019 di SMA Negeri 17 Bandung. Sampel pada penelitian ini berjumlah 30 responden yang mengalami dismenore dan memenuhi kriteria inklusi dan ekslusi. Sebanyak 15 responden diberikan paket nature atau sebagai kelompok intervensi dan 15 responden lainnya menggunakan metode atau cara yang mereka sendiri atau sebagai kelompok kontrol. Berikut ini disampaikan hasil penelitian yang disajikan dalam bentuk tabel.

\section{Gambaran Dismenore Pada Remaja Putri Di SMA Negeri 17 Bandung}

Pada tabel 1 distribusi frekuensi dismenore sebelum kelompok kontrol pada remaja putri di SMA Negeri 17 Bandung menunjukkan bahwa 9 orang $(60 \%)$ responden mengalami dismenore sedang dan 1 orang $(6,6 \%)$ responden mengalami dismenore berat sekali, sedangkan dismenore sesudahnya menunjukkan bahwa 7 orang $(46.7 \%)$ responden mengalami dismenore ringan dan 1 orang $(6,6 \%)$ responden mengalami dismenore berat.

\section{Tabel 1 Distribusi Frekuensi Dismenore Kelompok Kontrol Sebelum Dan Sesudah Pada Remaja Putri Di SMA Negeri 17 Bandung $(n=15)$}

\begin{tabular}{lcccc}
\hline $\begin{array}{c}\text { Dismenore } \\
\text { Kelompok Kontrol }\end{array}$ & $\begin{array}{c}\text { Sebelum } \\
(\mathrm{f})\end{array}$ & $\begin{array}{c}\text { Persentase } \\
(\%)\end{array}$ & $\begin{array}{c}\text { Sesudah } \\
(\mathrm{f})\end{array}$ & $\begin{array}{c}\text { Persentase } \\
(\%)\end{array}$ \\
\hline Ringan & 0 & 0 & 7 & 46.7 \\
Sedang & 9 & 60.0 & 7 & 46.7 \\
Berat & 5 & 33.3 & 1 & 6.6 \\
Berat sekali & 1 & 6.7 & 0 & 0 \\
\hline \multicolumn{1}{c}{ Total } & 15 & 100 & 15 & 100 \\
\hline
\end{tabular}

Tabel 2 Distribusi Frekuensi Dismenore Kelompok Intervensi Sebelum Dan Sesudah Pada Remaja Putri Di SMA Negeri 17 Bandung ( $\mathrm{n}=15)$

\begin{tabular}{lcccc}
\hline $\begin{array}{c}\text { Dismenore } \\
\text { Kelompok Intervensi }\end{array}$ & $\begin{array}{c}\text { Sebelum } \\
(\mathrm{f})\end{array}$ & $\begin{array}{c}\text { Persentase } \\
(\%)\end{array}$ & $\begin{array}{c}\text { Sesudah } \\
(\mathrm{f})\end{array}$ & $\begin{array}{c}\text { Persentase } \\
(\%)\end{array}$ \\
\hline Ringan & 0 & 0 & 13 & 86.7 \\
Sedang & 9 & 60.0 & 2 & 13.3 \\
Berat & 5 & 33.3 & 0 & 0 \\
Berat sekali & 1 & 6.7 & 0 & 0 \\
\hline \multicolumn{1}{c}{ Total } & 15 & 100 & 15 & 100 \\
\hline
\end{tabular}


Pada tabel 2 distribusi frekuensi dismenore sebelum kelompok intervensi pada remaja putri di SMA Negeri 17 Bandung menunjukkan bahwa 9 orang $(60 \%)$ responden mengalami dismenore sedang dan 1 orang $(6,7 \%)$ responden mengalami dismenore berat sekali, sedangkan dismenore sesudahnya menunjukkan bahwa 13 orang $(86.7 \%)$ responden mengalami dismenore ringan dan 2 orang $(13,3 \%)$ responden mengalami dismenore sedang
Perubahan Dismenore Kelompok Intervensi Dan Kelompok Kontrol Pada Remaja Putri Di SMA Negeri 17 Bandung

Hasil penelitian yang dilakukan menunjukkan adanya perubahan sebelum dan sesudah baik pada kelompok kontrol maupun kelompok intervensi. Untuk mengetahui perubahan tersebut maka digunakan uji wilcoxon rank test dengan hasil sebagai berikut :

Tabel 3 Perubahan Dismenore Kelompok Intervensi Pada Remaja Putri Di SMA Negeri 17 Bandung

\begin{tabular}{lccccc}
\hline Kelompok Intervensi & $\mathrm{N}$ & Median & Min & Max & P-Value \\
\hline Sebelum & 15 & 6,00 & 5 & 10 & \multirow{2}{*}{0,001} \\
Sesudah & 15 & 2,00 & 1 & 4 &
\end{tabular}

Berdasarkan tabel 3 di atas menunjukkan bahwa nilai median sebelum diberikan paket nature pada kelompok intervensi sebesar 6,00, sedangkan nilai median setelah diberikan sebesar 2,00. Penurunan nilai median sebelum dan sesudah pada kelompok intervensi sebesar 4,00. Kemudian setelah dilakukan uji Wilcoxon untuk melihat perubahan dismenore, dari hasil analisis tersebut menunjukkan bahwa ada perubahan dismenore dari tinggi ke rendah sebanyak 15 responden. Hasil uji Wilcoxon menunjukkan $p=0,001 \quad(p<0,05)$ artinya ada perubahan dismenore sebelum dan sesudah pada kelompok intervensi.

Tabel 4 Perubahan Dismenore Kelompok Kontrol Pada Remaja Putri Di SMA Negeri 17 Bandung

\begin{tabular}{lccccc}
\hline Kelompok Kontrol & N & Median & Min & Max & P-Value \\
\hline Sebelum & 15 & 6,00 & 5 & 10 & \multirow{2}{*}{0,001} \\
Sesudah & 15 & 4,00 & 1 & 7 &
\end{tabular}

Uji Wilcoxon Rank Test

Berdasarkan tabel 4 di atas menunjukkan bahwa nilai median sebelum melakukan metode atau cara yang mereka gunakan untuk mengurangi dismenore pada kelompok kontrol sebesar 6,00, sedangkan nilai median setelah mereka melakukan cara atau metode tersebut sebesar 4,00. Perubahan nilai median sebelum dan sesudah pada kelompok kontrol sebesar 2,00. Kemudian setelah dilakukan uji Wilcoxon untuk melihat perubahan dismenore, dari hasil analisis tersebut menunjukkan bahwa ada perubahan dismenore dari tinggi ke rendah sebanyak 15 responden. Hasil uji Wilcoxon menunjukkan $p=0,001 \quad(p<0,05)$ artinya ada perubahan dismenore sebelum dan sesudah pada kelompok kontrol.

\section{Tabel 5 Perbedaan Dismenore Kelompok Intervensi Dan Kelompok Kontrol Pada Remaja Putri Di SMA Negeri 17 Bandung}

\begin{tabular}{lccccc}
\hline Kelompok & $\mathrm{N}$ & Median & Min & Max & $p$ \\
\hline Kontrol & 15 & 2.00 & 1 & 4 & 0.007 \\
Intervensi & 15 & 3.00 & 2 & 6 & \\
\hline
\end{tabular}

Uji Wilcoxon Rank Test

Berdasarkan tabel 5 tersebut menunjukkan bahwa hasil uji statistik dengan wilcoxon rank test dapat dijelaskan bahwa median pada nilai perubahan kelompok kontrol adalah 2 dan pada kelompok intervensi adalah 3. Didapatkan pula hasil perubahan dismenore minimal pada kelompok kontrol adalah 1 dan perubahan dismenore maksimal adalah 4, sementara pada kelompok intervensi perubahan dismenore minimal adalah 2 dan perubahan dismenore maksimal adalah 6 . Hasil uji wilcoxon rank test diperoleh nilai $p$ 
value $=0,007 \quad(p<0,05)$, artinya ada perbedaan antara kelompok kontrol dan kelompok intervensi.

\section{PEMBAHASAN}

\section{Gambaran Dismenore Pada Remaja Putri Di SMA Negeri 17 Bandung}

Penelitian ini dilakukan pada remaja putri di SMA Negeri 17 Bandung dari total populasi 220 remaja putri peneliti mengambil sampel sebanyak 30 orang yang dilakukan dengan cara purposivesampling. Responden yang dijadikan sampel dalam penelitian ini adalah remaja putri di SMA Negeri 17 Bandung kelas X dan XI yang mengalami dismenore. Dari penelitian tersebut juga diketahui umur reponden berada pada rentang 1517 tahun.

Berdasarkan penelitian diatas menunjukkan dari jumlah sampel 30 remaja putri diantaranya 18 orang $(60 \%)$ remaja putri mengalami dismenore sedang, 10 orang $(33,3 \%)$ remaja putri mengalami dismenore berat dan $2(6,7 \%)$ remaja putri mengalami dismenore berat sekali. Penelitian yang dilakukan oleh Nuraeni (2015) pada remaja putri di SMK 1 Tapango Kecamatan Tapango Kabupaten Polewali Mandar menunjukkan dari jumlah sampel 30 remaja putri diantaranya 8 orang mengalami dismenore ringan, 12 orang mengalami dismenore sedang dan 10 orang mengalami dismenore berat.

Penelitian yang dilakukan oleh Mahendra (2016) pada Mahasiswi Fisioterapi di Universitas 'Aisyiyah Yogyakarta menunjukkan dari jumlah sampel 19 mahasiswi diantaranya 2 orang mengalami dismenore ringan, 13 orang mengalami dismenore sedang dan 4 orang mengalami dismenore berat.Penelitian yang dilakukan oleh Pangesti, dkk (2017) pada Mahasiswi Keperawatan Poltekkes Kemenkes Semarang menunjukkan dari jumlah sampel 44 mahasiswi diantaranya 7 orang mengalami dismenore ringan, 31 orang mengalami dismenore sedang dan 6 orang mengalami dismenore berat.

Menurut Galya, dkk (2001) dismenore sering terjadi pada perempuan usia muda, karena belum mencapai kematangan biologis (khususnya kematangan alat reproduksi yaitu pertumbuhan endometrium masih belum sempurna) dan psikologis. Dismenore biasanya mulai pada saat siklus telah menjadi ovulasi dalam tahun-tahun usia reproduksi dan siklus reguler. Puncak umur insiden perempuan yang mengalami dismenore adalah 20 sampai 24 tahun. Frekuensi nyeri akan menurun sesuai dengan bertambahnya usia. Hal ini diduga terjadi karena adanya kemunduran saraf rahim akibat penuaan
Dismenore setiap individu berbeda dipengaruhi oleh deskripsi individu tentang persepsi dan pengalaman dismenore. Dismenore terjadi karena ada peningkatan produksi prostaglandin. Peningkatan ini akan mengakibatkan kontraksi uterus dan vasokonstriksi pembuluh darah maka aliran darah yang menuju ke uterus menurun sehingga uterus tidak mendapat suplai oksigen yang adekuat sehingga menyebabkan nyeri

Berdasarkan hasil penelitian diatas dapat diketahui bahwa distribusi frekuensi dismenore pada remaja putri terbanyak berada pada dismenore sedang dengan persentase $60 \%$. Remaja putri yang mengalami dismenore sedang tersebut berdiam diri dikelas tanpa bisa melakukan aktivitas lain selain duduk dan memegang perutnya. Terlebih lagi remaja putri yang merasakan dismenore berat sekali, ada beberapa dari remaja putri tersebut yang pingsan. Ketika dismenore tidak banyak yang remaja putri lakukan untuk menguranginya, terkadang pergi ke UKS dan diberikan obat pereda nyeri, hal lain yang mereka lakukan yaitu minum air hangat atau memberi minyak telon didaerah perutnya.

Hal tersebut berhubungan dengan umur dan waktu haid pertama (menarche) remaja. Dismenore biasanya tidak muncul pada awal remaja mengalami menarche dan seiring remaja bertambah dewasa, biasanya nyeri haid yang dirasakan mulai berkurang. Dismenore sering terjadi kemungkinan lebih dari $25 \%$ dan $15 \%$ diantaranya mengalami nyeri pada saat menstruasi yang hebat biasanya dismenore timbul pada masa remaja yaitu sekitar 2-3 tahun setelah menstruasi pertama. Dismenore di tandai dengan gajala seperti kram pada perut bagian bawah dan nyeri punggung. Dismenore mulai timbul sesaat sesudah atau selama haid, mencapai puncaknya dalam waktu 24 jam dan setelah 2 hari akan menghilang.

\section{Perbedaan Dismenore Sebelum Dan Sesudah Pada Kelompok Intervensi Dan Kelompok Kontrol Remaja Putri Di SMA Negeri 17 Bandung}

Sebelum dilakukan pemberian pada kelompok kontrol dan kelompok intervensi, peneliti memberikan lembar pretest berupa skala nyeri NRS kepada responden untuk mengukur dismenore sebelum dan sesusah baik pada kelompok intervensi maupun kelompok kontrol. Hasil sebelum pada kelompok intervensi didapatkan bahwa responden lebih banyak merasakan dismenore sedang sebanyak 9 orang dengan persentase $(60 \%)$ dan dismenore berat sebanyak 5 orang dengan persentase $(33,3 \%)$. Dari hasil sebelum yang dilakukan pada kelompok intervensi 
didapatkan bahwa nilai median sebelum adalah 6,00 .

Berdasarkan hasil diatas, peneliti menyimpulkan bahwa sebagian besar responden merasakan dismenore sedang dan dismenore berat yang mana dismenore tersebut dapat mengganggu aktivitas serta mengganggu konsentrasi belajar, sehingga memerlukan istirahat dan memerlukan penanganan untuk menanganinya. Menurut penelitian bahwa dismenore pada responden disebabkan oleh tingginya kadar Prostaglandin dalam darah. Selama haid, uterus berkontraksi lebih kuat. Kadang-kadang ketika kontraksi seseorang itu akan merasakan nyeri. Kontraksi otot-otot rahim berlaku ketika prostaglandin dihasilkan. Prostaglandin adalah bahan kimia yang dibuat oleh lapisan rahim. Sebelum menstruasi, kadar prostaglandin meningkat.

Atas dasar itu disimpulkan bahwa prostaglandin yang dihasilkan uterus berperan dalam menimbulkan hiperaktivitas miometrium. Kontraksi miometrium yang disebabkan oleh prostaglandin akan mengurangi aliran darah, sehingga terjadi iskemia sel-sel miometrium yang mengakibatkan timbulnya nyeri spasmodik. Jika prostaglandin dilepaskan dalam jumlah berlebihan ke dalam peredaran darah,maka akan timbul efek sistemik seperti diare, mual, muntah

Setelah pemberian paket nature yang terdiri dari konsumsi air putih, abdominal stretching exercise, dan konsumsi buah pisang raja pada 5-7 hari sebelum menstruasi, kemudian pada hari pertama menstruasi responden kembali melakukan pengisian lembar numeric rating scale. Dari posttest tersebut menunjukkan bahwa responden yang merasakan dismenore ringan sebanyak 13 orang $(86,7 \%)$ dan dismenore sedang sebanyak 2 orang $(13,3 \%)$. Dari hasil posttest yang dilakukan peneliti didapatkan bahwa nilai median setelah 2,00 dengan selisih penurunan sebesar 4,00. Dan hasil uji wilcoxon rank test didapatkan nilai $p=0,001$ $(p<0,05)$ artinya ada perbedaan dismenore sebelum dan sesudah pada kelompok intervensi.

Hasil sebelum pada kelompok kontrol didapatkan bahwa responden lebih banyak merasakan dismenore sedang sebanyak 9 orang dengan persentase $(60 \%)$ dan dismenore berat sebanyak 5 orang dengan persentase $(33,3 \%)$. Dari hasil sebelum yang dilakukan pada kelompok intervensi didapatkan bahwa nilai median sebelum adalah 6,00. Berdasarkan hasil diatas, peneliti menyimpulkan bahwa sebagian besar responden merasakan dismenore sedang dan dismenore berat yang mana dismenore tersebut dapat mengganggu aktivitas serta mengganggu konsentrasi belajar, sehingga memerlukan istirahat dan memerlukan penanganan untuk menanganinya.

Setelah melakukan cara atau metode (seperti minum air hangat, kompres air panas atau membalurkan minyak kayu putih) yang biasa digunakan reponden pada kelompok kontrol kemudian pada hari pertama menstruasi responden kembali melakukan pengisian lembar numeric rating scale. Dari posttest tersebut menunjukkan bahwa responden yang merasakan dismenore ringan dan sedang berjumlah sama yakni sebanyak 7 orang $(46,7 \%)$ dan dismenore berat sebanyak 1 orang $(6,6 \%)$. Dari hasil posttest yang dilakukan peneliti didapatkan bahwa nilai median setelah 4,00 dengan selisih penurunan sebesar 2,00. Dan hasil uji wilcoxon rank test didapatkan nilai $p=0,001(p<0,05)$ artinya ada perbedaan dismenore sebelum dan sesudah pada kelompok kontrol.

Berdasarkan tabel 4.5 diatas menunjukkan bahwa hasil uji statistik dengan chi square dapat dijelaskan bahwa pada kelompok intervensi dismenore terbanyak berada pada ringan sebanyak 13 orang $(86,7 \%)$, sedangkan pada kelompok kontrol dismenore yang terbanyak berada pada ringan dan sedang dengan jumlah yang sama sebanyak 7 orang $(46,7 \%)$. Berdasarkan uji wilcoxon rank test diperoleh nilai $p$ value $=0,007$ $(p>0,05)$, artinya ada perbedaan antara kelompok kontrol dan kelompok intervensi.

Peneliti menyimpulkan bahwa setelah diberikan paket nature (konsumsi air putih, abdominal stretching exercise, dan konsumsi buah pisang raja) pada kelompok kontrol dan setelah melakukan metode atau cara yang biasa dilakukan (minum air hangat, kompres air panas atau membalurkan minyak kayu putih) dapat menyebabkan penurunan dismenore pada remaja putri.

Menurut Laila (2011) Kompres hangat dapat meminimalkan ketegangan otot. Setelah otot rileks, rasa nyeri pun akan berkurang, berolahraga secara teratur dapat mengurangi stress yang timbul ketika menstruasi. Selain itu berolahraga juga dapat meningkatkan produksi hormoneendorphin otak yang merupakan penawar rasa sakit yang alami dalam tubuh, minum air putih sebanyak 8 gelas sehari mampu mengurangi rasa nyeri saat menstruasi. Minum air puth saat menstruasi dilakukan untukmencegah terjadinya penggumpalan darah dan melancarkan peredaran darah dan mengkonsumsi makanan yang banyak mengandung kalsium dan makanan segar, seperti sayuran, buah-buahan, ikan, daging, dan makanan yang mengandung vitamin $\mathrm{B} 6$ berguna mengurangi atau mencegah dismenore. 


\section{Efektifitas Pemberian Paket Nature Terhadap Dismenore}

Hasil uji analisis bivariat menggunakan wilcoxon rank test, kelompok intervensi memperoleh nilai $p=0,001 \quad(p \leq 0,05)$ yang menunjukkan bahwa paket nature efektif dalam menurunkan dismenore. Dapat disimpulkan bahwa Ho ditolak dan $\mathrm{Ha}$ diterima, yang berarti paket nature efektif terhadap dismenore pada remaja purti di SMA Negeri 17 Bandung.

Penelitian yang dilakukan oleh Ratnaningsih (2011) ) mengenai paket pereda yang terdiri dari konsumsi air putih dan abdominal stretching exercise menunjukkan hasil bahwa paket peredaefektif dalam menurunkan intensitas nyeri pada remaja dengan dismenore. Penelitian Wahyuni (2012) tentang pengaruh abdominal stretching exercise terhadap dismenore pada remaja putri menunjukkan bahwa ada pengaruh abdominal stretching exercise terhadap intensitas dismenore.

Penelitian yang dilakukan oleh Indriastuti (2008) di Panti Asuhan Nurul Huda Az-Zuhdi Kelurahan Meteseh Kecamatan Tembalang yang membuktikan bahwa ada pengaruh yang signifikan sesudah diberikan terapi air putih. Hasil penelitian ini sejalan dengan penelitian yang dilakukan oleh Edo, Erma dan Ririn (2016) di SMA Muhammadiyah 01 Malang pada siswi remaja menunjukkan konsumsi pisang raja efektif terhadap penurunan nyeri haid pada dismenore.

Batmanghelidj (2007) yang menyatakan minum air dapat mengurangi nyeri menstruasi, air dapat mengencerkan darah dan mencegah penggumpalan darah ketika ia beredar ke seluruh tubuh serta sumber utama energi bagi tubuh. Abdominal stretching exercise merupakan latihan fisik peregangan otot terutama pada area perut yang dilakukan kurang lebih selama 10-15 menit latihan fisik ini ditujukan untuk meningkatkan kekuatan otot, daya tahan dan fleksibilitis otot (Thermacare, 2010). Menurut Sulistyanto (2018) bahwa pisang raja memiliki kandungan kalium yang tinggi, yaitu lebih dari $400 \mathrm{mg}$ kalium per buah pisang ukuran sedang. Menurut para ahli gizi, kalium sangat diperlukan saraf, membantu fungsi otot dan menjaga keseimbangan cairan dalam tubuh. Kalium dalam pisang bisa membantu mencegah kram otot setelah latihan.

Dari beberapa hasil penelitian sejenis yang telah dilakukan, dapat disimpulkan hasil penelitian ini sesuai dengan hasil penelitian sejenis tersebut bahwa paket nature efektif terhadap dismenore pada remaja putri di SMA Negeri 17 Bandung.

\section{KESIMPULAN}

Berdasarkan hasil penelitian dan pembahasan tentang efektifitas paket nature terhadap dismenore pada remaja putri di SMA Negeri 17 Bandung, dapat di simpulkan bahwa :Distribusi frekuensi dismenore pada kelompok kontrol dan kelompok intervensi terbanyak berada pada dismenore sedang dengan persentase $60 \%$, dismenore berat $33,3 \%$ dan dismenore berat sekali $6,7 \%$.Terdapat penurunan dismenore pada kelompok kontrol, yaitu dismenore sebelum melakukan cara atau metode yang biasa dilakukan memiliki nilai median sebesar 6,00 dan sesudah melakukan cara atau metode yang biasa dilakukan mengalami penurunan menjadi 4,00. Uji wilcoxon rank test menunjukkan hasil $p=0,001 \quad(p<0,05)$ berarti ada penurunan dismenore sebelum dan sesudah pada kelompok kontrol.Terdapat perbedaan dismenore pada kelompok intervensi, yaitu dismenore sebelum diberikan paket nature memiliki nilai median sebesar 6,00 dan sesudah diberikan paket nature mengalami penurunan menjadi 2,00. Uji wilcoxon rank test menunjukkan hasil $p=0,001 \quad(p<0,05)$ berarti ada penurunan dismenore sebelum dan sesudah pada kelompok intervensi.Terdapat perbedaan antara kelompok intervensi dan kelompok kontrol dengan hasil uji wilcoxon rank test $p=0,007(p<0,05)$.

\section{SARAN}

Petugas kesehatan diharapkan dapat meningkatkan upaya pencegahan dismenore pada remaja putri di Sekolah Menengah Atas serta dapat menjalin kerja sama dengan petugas UKS.

\section{DAFTAR PUSTAKA}

Agusta., Edo, Et Al (2016). Efektivitas Konsumsi Pisang Raja Terhadap Penurunan Nyeri Haid Pada Dismenorheaprimer Siswi SMA Muhammadiyah 01 Malang

Anurogo, D.\& Wulandari, A. (2011). Cara Jitu Mengatasi Nyeri Haid. Yogyakarta: ANDI Yogyakarta.

Astarto, Winarto Nanang., (2011). Kupas Tuntas Kelainan Haid. Jakarta: CV Sagung Seto, 2011.

Bavil, Dina Abadi, Dolatian, Mahrokh, Mahmoodi, Zohreh, Baghban, Alireza, Akbarzadeh. (2016). Comparison Of Lifestyle Of Young Woman With And Without Dysmenorrhea. Iran : Electronic Physician

Chang, E., Daly, J., Dan Elliott, D., (2010) Patofisiologi Aplikasi Pada Praktik Keperawatan, 112-113, Jakarta, EGC. 
Dean, Carolyn. (2011). Magnesium. Active Interest Media Inc. California. P15-16

Depkes RI (2010). Profil Kesehatan Indonesia. Jakarta: Depkes RI

Diyan, Indriyani. (2013). Keperawatan Maternitas Pada Area Perawatan Antenatal. Yogyakarta: Graha IImu

Douglas, C., Dkk (2012). Potter \& Perry's fundamental of Nursing-Australian Version. Australia: Elsevier.

Fridintya, Galuh, A (2011). Perbedaan Efektivitas Pemberian Jus Pisang Ambon Danjus Pisang Raja Dalam Mengatasi Kelelahan Otot Pada Tikus Wistar. From Http://Eprints.Undip.Ac.Id Diakses Pada Tanggal 16 Maret 2019

Icemi Sukarni K, \& Wahyu P. (2013). Buku Ajar Keperawatan Maternitas Dilengkapi Contoh Askep. Yogyakarta: Nuha Medika.

Irianto, Koes. (2015). Kesehatan Reproduksi. Bandung : Alfabeta

Kumalasari.(2012). Kesehatan Reproduksi. Jakarta : Rinekacipta

Kurniawati, Dewi \& Kusumawati, Yuli (2011). Pengaruh Dismenore Terhadap Aktivitas Pada Siswi SMK. From Https://Journal.Unnes.Ac.Id Diakses Pada Tanggal 16 Maret 2019

Kusmiran, E (2011). Kesehatan Reproduksi Remaja Dan Wanita. Jakarta: Salemba Medika

Laila, N. N. (2011). Kesehatan Reproduksi Remaja Dan Wanita. Jakarta : Salemba Medika

Lely Noormindhawati Dan Farida Wahyu Ningtyias (2016). Jus Sehat Untuk Sembuhkan Berbagai Penyakit Plus Diet Jus Berdasarkan Golongan Darah A B O Ab. Penerbit : Dua Media

Marmi, (2014). Kesehatan Reproduksi. Yogyakarta: Pustaka Pelajar

Muhammad, A. (2011). Kedahsyatan Air Putih Untuk Ragam Terapi Kesehatan. Yogyakarta: Penerbit DIVA Press

Notoatmodjo, S. (2012). Metodologi Penelitian Kesehatan. Jakarta : Rineka Cipta
Prawirohardjo, Sarwono. (2011). Ilmu Kandungan. Jakarta : PT Bina Pustaka

Progestian, P. (2010). Cara Menentukan Masa Subur. Swarna Bumi : Jakarta

Ratnaningsih., Et Al., (2011). Efektivitas Paket Pereda Terhadap Intensitas Nyeri Pada Remaja Dengan Dismenore Di SMAN Kecamatan Curup. Tesis. Jakarta: Universitas Indonesia

Sastroasmoro,Dan Sofyan Ismael. (2010). DasarDasar Metodologi Penelitian Klinis, Edisi Ketiga In: Pemilihan Subjek Penelitian Dan Desain Penelitian. Jakarta: Sagung Seto

Sinaga Ernawati, Dkk (2017). Manajemen Kesehatan Menstruasi. Universitas Nasional, IWWASH \& Global One

Sinclair, Constance, (2010). Kondisi Ginekologis Dan Pertimbangan Kehamilan Serta Kontrasepsi. Dalam : Buku Saku Kebidanan. Jakarta : EGC, 592-597

Soetjiningsih. (2010). Tumbuh Kembang Remaja Dan Permasalahannya. Jakarta : Sagungseto

Sugiyono. (2012). Metode Penelitian Kuantitatif Kualitatif Dan R\&D. Bandung : Alfabeta.

Sulistyanto. (2018). Kiat Hidup Sukses Dan Berumur Panjang. Yogyakarta: ANDI

Suryani \& Hendryadi. (2015). Metode Riset Kuantitatif Teori Dan Aplikasi Pada Penelitian Bidang Manajemen Dan Ekonomi Islam. Jakarta: Prenada Media Group.

Thermacare, (2010). Abdominal Stretching Exercise For Menstrual Pain. Http://Www.Chiromax.Com/Media/Abstretc h.Pdf.

World Health Organization.Who.Int. Micronutrient Deficiencies. [Online] World Health Organization Global, (2012). [Dikutip: 08 Desember 2018.] Http://Www.Who.Int

Yosephin, Betty (2018). Tuntutan Praktis Menghitung Kebutuhan Gizi. Ed 1 Yogyakarta: ANDI 